\title{
The necessity of developing knowledge map of the world in Earth Sciences and mines field studies based on research activities: a case study of Iran
}

\author{
Babak Asul ${ }^{14^{*}}$, Masoumeh Eghball ${ }^{2}$, Narges Ghamami ${ }^{3}$, Hassan Didari Abbasabad ${ }^{4}$, Behrooz Rasuli ${ }^{5}$, Fereydoun Rezaie ${ }^{6}$ \\ 1. Ph.D. student of Economic Geology, College of Science, Faculty of Geology, University of Tehran, Tehran, Iran \\ 2. Master's student, Research Institute for Earth Sciences, Geological Survey of Iran, Tehran, Iran \\ 3. Executive secretary of earth sciences quarterly magazine, Geological Survey of Iran, Tehran, Iran \\ 4. Expert of the Mineral exploration Department, Geological Survey of Iran, Tehran, Iran \\ 5. Ph.D. in Library and Information Science, Iranian Research Institute for Information Science and Technology \\ 6. Associated Professor of Engineering geology, Research Institute for Earth Sciences, Geological Survey of Iran, Iran

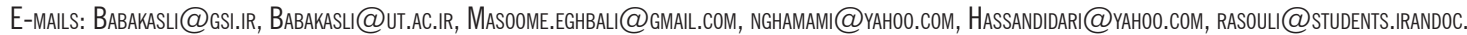 \\ AC.IR, REZAIE8@YAHO0.FR
}

Abstract: As Robert Merton believes, as Science is a social construct, researchers in a certain research community have to share their findings. However, one of the main activities of knowledge management is the sharing knowledge through formal channels, including theses and dissertations, books, articles, conferences, etc., because it has a significant impact on the advancement of sciences and will improve the quality of R\&D activities, organizational performance, and the achievement of researchers to competitive advantage. Current global databases such as Scopus, web of science, Google Scholar, as well as academic social network sites (SNS) such as Researchgate and Academia.edu are not successful in demonstrating the dynamics of knowledge In order to understand the dynamics of science, scientific collaboration, industrialization of the countries, we analyze and draw a strategic map in Earth Sciences and Mines of Iran's to help science and technology policy-makers, based on reviewing of the research activities of researchers in different dimensions of geology and mining field study. Through a scientometrics approach, 8431 publications including thesis (1967 to 2015) and papers (1991 to 2016) in two special fields of geology and mining were analyzed. According to the findings, a total of 127 universities in the 80 field study and 294 disciplines in the field of geosciences, 52 universities, and 13 disciplines in the field of geology and 36 universities and 26 disciplines in the field of mining and geophysics have been involved in the production of theses. Among them, the largest amount of publications in the field of geosciences includes fields of geology, mining engineering, civil engineering, natural geography, natural resources engineering respectively. There is an incremental growth of scientific activities in the mineral sector of Iran but unacceptable trend in relation to the number of minerals deposits, mines as well as the total number of mines in Iran. According to the International Standard Industrial Classification (ISIC), researchers in this area are more interested and performed the most scientific activity in metal (07), non-metallic and decorative (08), and oil and gas (05) section and (071), (081), (051)categories respectively. Also developing the statistical and GIS Mapping of research activities show low index of relationship between industrial needs and university research activities, lowest to medium (dispersive) overlap and duplicates, and insufficient research activities in various fields of the earth's sciences and subsequently lowest growth of quantity of the publications in this field so far for geosciences education of Iran despite the advances in the field of geosciences over the past 50 years. These findings improved our knowledge and helped us to know about our deficiencies/potential so that we suggest to develop a new generation of freely geosciences research activities databases based on web-GIS and scientometrics for researches/ers in the world in the $3^{\text {rd }}$ millennium. In fact, understanding of these and drawing the universal research activities strategic map in the geosciences field study will help us to make an appropriate policies and decisions, improving initiatives and creativity, shed light on developing multi-dimensions of geosciences.

\section{Manuscript:}

Received: Selected paper, Quadrennial Conference of the International Geoscience Education Organization (IGEO)

Accepted: 26/10/2018

Citation: Asli, B., Eghbali, M., E., Ghamami, N., Abbasabad, H. D., Rasuli, B., \& Rezaie, F. 2019. The necessity of developing knowledge map of the world in Earth Sciences and mines field studies based on research activities: a case study of Iran. Terræ Didatica, 15, 1-7, e019007. doi:10.20396/td.v15i0.8654661 Keywords: Earth Sciences, Mines, Scientometrics, Research Policy, International Standard Industrial Classification, dynamics of science. 


\section{Introduction}

In the current age, along with increasing the volume of information, due to valuable content of scientific and research journals, through scientific and research content, is considered as one of the important sources in research, transferring scientific information and technological findings among researchers, and as one of the indicators index related to scientific development in societies (Osareh, 1998, Nasseri \& Diani, 2010, SCImago, 2012; Erfanmanesh \& Keshavarzian, 2016) so that this scientific information's act as best tools for evaluating scientometric activities and has main source to study the dynamics of science and changes in scientific texts, intellectual cooperation, social and / or cognitive structures of researchers (Mir Jalili \& Osareh, 2012), studying of the scientific interdependence of countries, especially developing countries, with the exchange of scientific and technological interactions, and the promotion of and development and growth index as an indispensable necessity (Reza gholi lalani, 2011). In fact, knowledge sharing leads to the creation of new knowledge, innovation, and, consequently, organizational performance improvement (Sohail \& Daud, 2009), in the form of sharing knowledge between employees and creating an organizational knowledge base and shaping the behavior of knowledge (Reychav \& Weisberg, 2010; Seba et al., 2012, Akhavan et al., 2014).

Meanwhile, the research policy makers in various societies, including Iran, emphasized on the "effectiveness of research (impact's)", increasing research activities usages of country and creating a high degree of solidarity between scientific and economic progress, in order to achieve a development goals including applicable research on community improvement in top-notch documents for the use of senior executives and senior advisers regarding its importance, necessity, and its impact on the community Anandajayasekeram \& Martella 1999; Gaunand et al., 2015, Smith et al., 2002).

In this regard, in some societies such as research organizations, they will receive only additional or even past funding, which they provide a clear definition of the expected research impacts on research work and providing clear technical and economic studies on cost-benefit research outputs (Griffiths 1993), distinction between conceptual difference such as some words, outputs and results, and their effects (Penfield et al., 2014).
Parallel with emphasizing increasing global attention to the effectiveness of research activities, it is expected that our country to be moved on measurement of the production of science and measuring the effectiveness of science) (Fattahi, 2014).

The importance of paying attention to the impact of research activates and citation analysis of research activity is result from this fact that solving all developmental problems as well as taking any step forward in a coordinated manner and at the national level, only will be achieved through the implementation of research oriented applicationand be matching with the results of this type of research, because according to the statistics of the advanced countries, there is showing a clearly high correlation between economic growth and applicable researches so that it is raising the economic growth index in those countries (Gazni et al., 2012).

Earth science is considered as one of the most important affecting factors in economic sectors, especially the mining and related industries in the country, therefore investment and special attention to this sector is important and inevitable because economic of Iran's should be considered based on mine economic (metallic and nonmetallic), attention to this sector of economic development, will effect on many sector and improve our situation in world level in many issues such as employment and independence of the country, preservation of national security, political and social dimensions (Kashanian, 2013). The purpose of this research is to investigate scientific-research activities (thesis and paper) published in the field of geosciences (geology and mining) in order to briefly understanding scientific production, scientific cooperation, co-authorship, co-authorship network, scientific policy, scientific relationship of scholars, on organizational performance, and how research activities are related to industrial activities to accurately map the strategic plan of the Earth's Sciences for the future.

Garfield (1970), the founder of Institute for Scientific Information (ISI), has attracted to visualizing of research activities of many other researchers on the world in the field of science in the 1970's decades. Also extensive studies carried out by various researches based on scientometrics and scientific collaboration dimension such as consideration of International Collaboration in relation to Iranian Scientific Publications (1995-1995) (Wilson \& Osareh, 2002); Scientometric analysis of Iranian Science and Technology Publications (2002-2005) (Wilson \& Osareh,, 2003): Modeling of networks and coopera- 
tion pattern between academic staff of the Geological Survey of Iran (GSI) (Kashanian 1392); also extensive studies carried out on many different aspect of geosciences such as scientomerty (San Andreas Fault System, Gizzi, 2017; disciplinary diversity and international collaboration, Gautam, 2017) application of GIS in geoscience (Qu et al., 2001, Reynolds et al., 2006, Sinha et al., 2010, Li \& Xiao, 2013, Song \& Jiang, 2013, Giorgis, 2015, Kouziokas, 2016, Ritschel et al., 2012). Simons et al. (2012) emphasized to developing sharing geoscience knowledge because it is so necessary to a developing initiatives and provide an opportunity to conduct many queries (Taber et al., 2012); Howard et al., (2009) suggested to developing a geoscience knowledge framework for a national geological survey organization. Loudon, (2006) considered transforming geological survey knowledge to a new service-oriented infrastructure. Li et al. (2017) studied bibliometric and visual analysis of global geo-ontology research from 1999 till 2014. Lanucara et al. (2017) researched on resolving software barriers on sharing and visualization of geological data on the web.

\section{Methodology and Tools}

The present research is a survey-analytical-descriptive type that has a scientistic approach. Based on the statistics and information collected by the experts of the field of geosciences, there are 8431 case theses loaded at the Ganj base from the achievements of the Iranian Institute of Science and Technology (Irandoc) And authoritative scientific-research publications approved by the Ministry of Science, Research and Technology, indexed at the citation database of the Islamic Socialist Science Association (ISC), during the time period (13941346) for theses, as well as for scientific articles, A research produced during the time interval (19651999) in two special fields of geology and mining engineering as the main data Valid for this research have formed.

Collected data has been analyzed using various tools such as Excel, Access, and other customizable software. In this research, all of the collected data consisting of thesis and published papers were entered into two languages (English-Persian), after consolidating and correction, the number of 1751 dissertations were removed due to lack of correct information. so after this steps and based on higher education valid indicators, the geosciences data classified based on gender, field of study, area, university, scientific co-operation (cc) index between the authors, and applied indicators in the field of mining industry (mineral categories), key topics were categorized in each research work. So that they are studied based on mining industrial parameters index in the earth sciences field study finally knowledge map of data was drawn in GIS and scientomerics software.

\section{Findings}

The distribution of the number of research activities in the geosciences related to higher education institutions of the country was calculated in terms of the dependence of the center, the administration type and study course. As it is clear in Figure 1 , the number of research activities conducted by graduate students in different fields of geoscience, by gender, academic degree shows that the number of 6448 master theses and $432 \mathrm{Ph}$.D. dissertation at different institutions has been registered in different institutions of higher education. Distribution of theses registered in the Ganj in the field of geosciences are increasing from 2 volumes in 1967 to 391 volumes in 2015, in the field of geology show increasing from 1 volume in 1966 to 423 volumes in 2015 and in mining field from 1 volume in 1967 to 283 volumes of thesis in 2015 .

In order to study more precisely of data, this study has been limited to studying statistical data related to two main areas of geosciences (geology and mining). As it is shown on Figure 1, the Geology and Mining field study have 3510 and 1711 theses, (Total $=5221)$ of the total theses passed in universities and institutes of higher education which it has dedicated $76 \%$ of the total statistical society of this research Among, the number of 3241 and 268 thesis and dissertations are related to master's theses and doctorate dissertations in 12 geology disciplines and the number of 1637 and 74 as same as it has related to the number of 24 disciplines in mining, oil and geophysical field studies respectively. Considering the statistical data of two field study are indicating three periods of time for graduate students research activities growth in this section; the first period (1957-1990) are characterized with a very small increase in the number of theses and graduates, the second period (1991-2007) are characterized with medium growth of the graduates, and the third period (2007 to 2015) are characterized with the increasing the number of research activities and consequently, the 


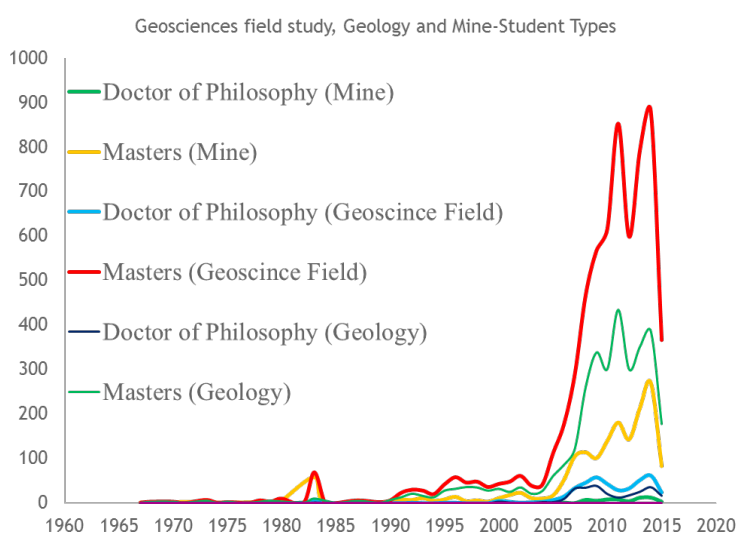

Figure 1. Distribution diagram of students in the field of Earth Sciences and Mining by year and grade

great growth of graduates in this field.

Considering scientometrics structure of 6880 submitted research activities in Ganj database (Irandoc) from 1967 until 2014 on VOSviewer software revealed 3947 prolific authors for Geosciences education of Iran. Minimum threshold document of an author (10) during the period of time, resulted 349 of the prolific co-authorship (accounting for $0 / 08$ of the prolific authors) in 21 clusters circled by solid lines (Fig. 2). The largest and smallest subnetwork has 29 and 2 collaborators which they are numbers accounting for $0 / 08$ and 0.005 of the prolific authors research activity co-authorship (Fig. 2).

Visualizing of the research data in the Web-GIS and considering of their industrialization based on suggested commodity classification by International Standard Industrial Classification (ISIC) show an incremental growth of scientific activities in the mineral sector of Iran but unacceptable trend in relation to the number of minerals deposits, mines as well as the total number of mines in Iran.

Generally according to the ISIC, researchers in this area are more interested and performed the most scientific activity which it has dedicated $13 \%$ of the total statistical society this research, it has related to the number of 5 disciplines consisting geology $(\mathrm{G})$, mining $(\mathrm{M})$, oil and geophysical field studies respectively. The geology and mining filed studies researcher show more interesting to investigate in Part B (G. 844; M, 408) of ISIC. Detailed consideration of the research activities in the field of mining industrializations show basically most scientific activity in Sections of 07 (metal with showing G, 283; M, 306), 08 (non-metallic and decorative with showing $\mathrm{G}, 153 ; \mathrm{M}, 22$ ), and 05 (oil and gas with showing $\mathrm{G}, 33 ; \mathrm{M}, 2$ ) and group of 071 (with showing G, 283; M, 335), 081 (with showing $G, 153$; M, 22), 051 (with showing $G, 51$; M, 5) respectively (Fig. 3).

In order to consider detailed of distribution of the number of conducted research activities in the geosciences field study related to ISIC classification show that the number of 862 (total $=6,448$ ) master's theses and 41 (432) dissertation in Ph.D. level at different institutions has been conducted in different institutions of higher education. Master and $\mathrm{Ph}$. D researcher show more interesting to investigate in Part B (Ms. 859; Ph.D. 41) rather than Part 5 (Ms. 41; Ph.D. 0), which they are belonging to Group 2 of ISIC. Detailed consideration of the researches show authors and their collaboration

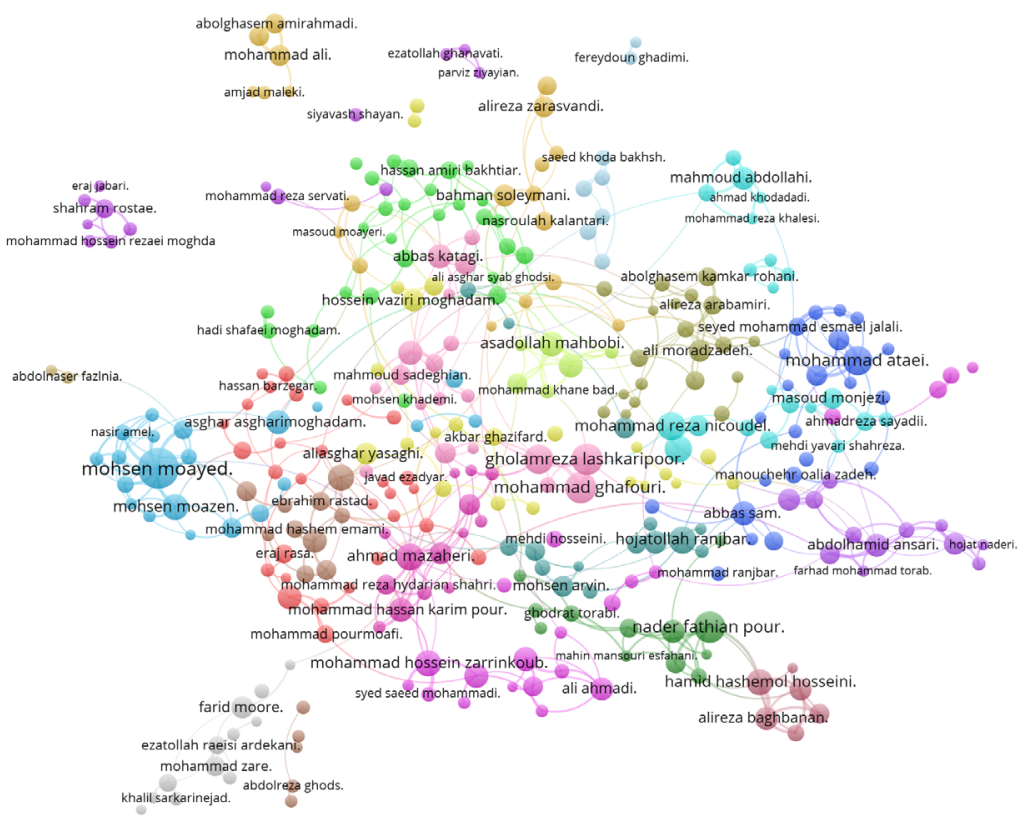

Figure 2. Scientometrics structure of 6,880 submitted research activities in Ganj database (Irandoc) from 1967 until 2014 on VOSviewer software resulted 349 of the prolific co-authorship for 3,947 prolific authors for Geosciences education of Iran 


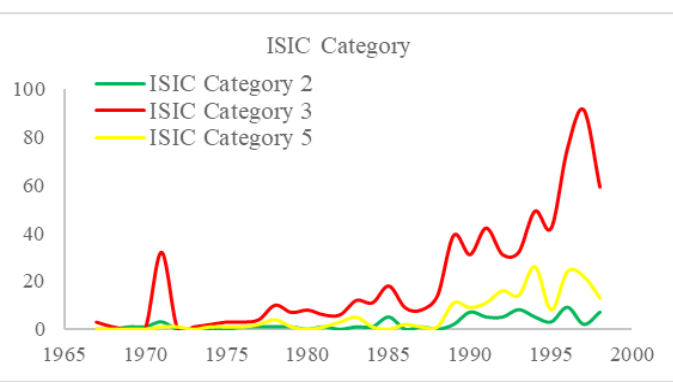

Figure 3. Distribution diagram of research activities according to the ISIC in the field of Earth Sciences and Mining by year

team worker show more interesting to performing research activates in group 071 (Ms. 622; $\mathrm{PhD}$. 27) rather than 081 (Ms. 168; PhD. 12) and 051 (Ms. 69; PhD. 2) and in Sections of 07 (metal with showing Ms, 592; PhD., 27), 08 (non-metallic and decorative with showing Ms, 168; P.hD., 12), and 081 (oil and gas with showing Ms, 37; PhD., 1).

In the case of higher education institutions dependency, it shows that the performed researches have been done in governmental type (Part 5, 3; Part B, rather than non-governmental type institutions. According to the ISIC section classification and higher education institutions dependency, governmental institution is performed more industrialization with most scientific activity in Sections of 07 (metal with showing $\mathrm{Ga}, 613$; NGa, 6), 08 (non-metallic and decorative with showing Governmental (Go), 176; Non-Governmental (Ngo), 4), and 05 (oil and gas with showing Go,
36; NGo, 2) and group of 071 (with showing Go, 36; NGo, 2), 05 (with showing Go, 36; NGo, 2), 2 (with showing Go, 36; NGo, 2) respectively.

Considering Industrialized research activities scientometry structure of 932 classified research activities based on ISIC from 1967 until 2014 on VOSviewer software revealed 624 prolific authors for Geosciences education of Iran. Minimum threshold document of an author (2) during the period of time, resulted 281 ( 0.45 of 624 and 0.07 of 3947) the prolific co-authorship (accounting for 0.45 of 624 and 0.07 of 3947 of the prolific authors) in 21 clusters circled by solid lines (Fig. 3). The largest and smallest subnetwork has 19 and 4 collaborators which they are numbers accounting for $0 / 03$ and 0.006 of the 624 prolific authors research activity co-authorship (Fig. 4).

\section{Conclusion}

"During the past decade, advances in information technology have ignited a revolution in decision-making, from business to sports to policing. Previously, decisions in these areas had been heavily influenced by factors other than empirical evidence, including personal experience or observation, instinct, hype, and dogma or belief. The ability to collect and analyze large amounts of data, however, has allowed decision makers to cut through these potential distortions to discover what really works." (Esty \& Rushing,

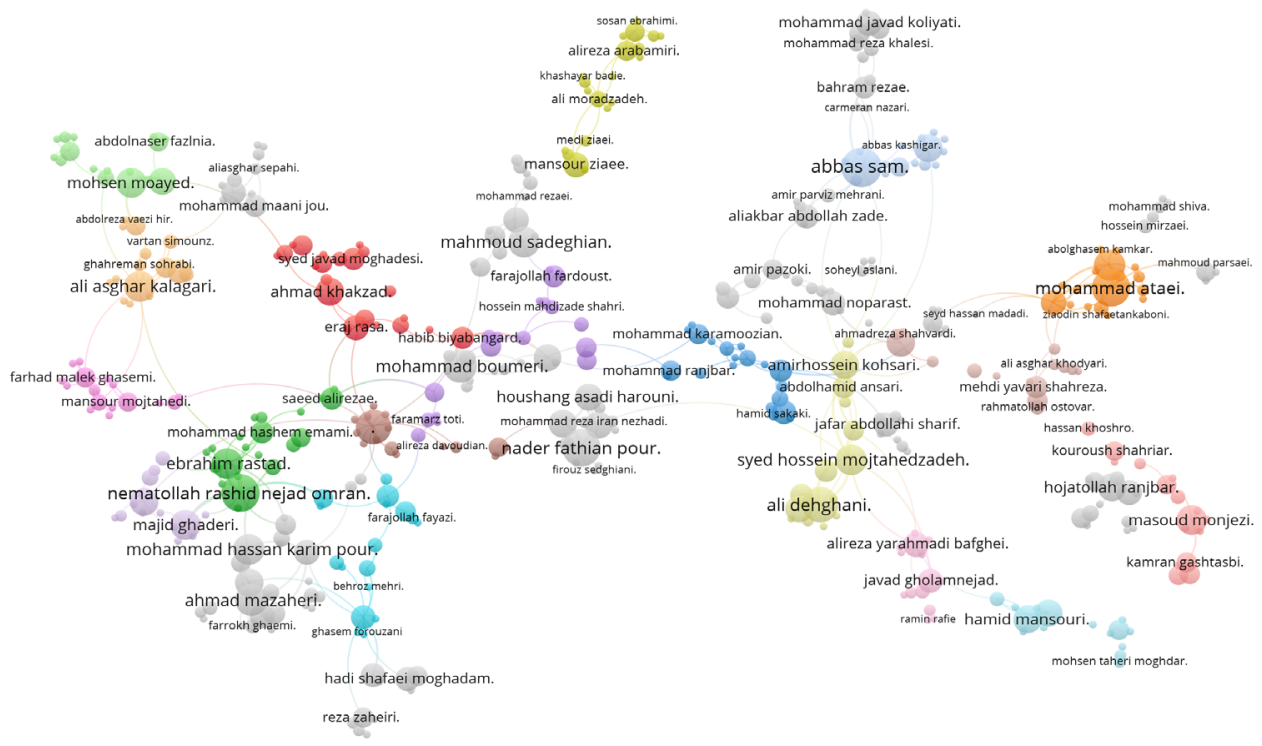

Figure 4. Scientometrics structure of 932 submitted Industrialized research activities in Ganj database (Irandoc) from 1967 until 2014 on VOSviewer software resulted 457 of the prolific co-authorship for 624 3,947 prolific authors in field of Geosciences education of Iran 
2007) $)^{1}$. Data-driven policy making is one of the most important approaches for planning science, technology, and innovation (STI) though analyzing bid data in different levels.

However, geosciences are an academic field, which is remained unaddressed according to Scientometrics analysis in Iran. Also a lack of reliable and structured data is one of the key limitations in this study, which may impact on the findings. Ganj database is the only source of data for theses and dissertations, which has some limitations in organization. Since there is no a unique code for authors, like ResearcherID or ORCID, analyzing data and reporting exact findings is not easy and reliable. However, in this research the analysis regarding this matter were not reported. Improving Ganj is necessary for providing reliable data.

Findings showed show low index of relationship between industrial needs and university research activities, lowest to medium (dispersive) overlap and duplicates, and insufficient research activities in various fields of the earth's sciences and subsequently lowest growth of quantity of the publications in this field so far for geosciences education of Iran despite the advances in the field of geosciences over the past 50 years.

\section{Acknowledgements}

The authors are particularly grateful to Nees Jan van Eck and Ludo Waltman for developing VOSviewer Software. We would like to say our thanks to the Geological Survey of Iran and University of Tehran for any kind helps. Also, we would like to say special thanks to Shankar Rajasekharaiah as Chair of International Geoscience Education Organisation (IGEO) and 8th GeoSciEd conference 2018 organizer teams at Campinas, Brazil, We also want to say special thanks to Ana Carolina Caires (MCI Brasil | São Paulo), Diego Silva (MCI Brasil | São Paulo). Also, we would like to thank Mohammad Tavakolizadeh Ravari (Department of Information Science \& Knowledge, Yazd University) and Zohreh Soltani (Data Mangment, Central Library Department, Shahid Bahonar University of Kerman) for encouraging during the research study. Also the Authors would like to expend our spacial gratitude's to Fatemeh Nikoukar, Vajiheh Mir Hosseini, Misha Sondosi, Shirin Farkhani, Mohamamd Lotfi, Sedigheh Jadavi, Elham Esfahani, Farzaneh Zinali Kermani, Hadi Moddaress, Mohammad Reza Sayareh, Iman Entezam, Yousef

1 issues.org/23-4/esty-2/
Asgarinezhad, Mehdi Chakeri, Alireza Ameri, Ahmad Samavat, Ghorban Karimi, Amir Mohammad Vaziri repectively. We also want to say special thanks to Prof Dr. Celso Dal Re Carneiro as Editor-in-Chief, of Terra Didatica magzin, Sueli Yoshinaga Pereira, Fresia, Pedro Wagner Gonçalves and rewiwer name in acknowledgement part of the paper. which greatly improved this manuscript.

\section{References}

Akhavan, P., \& Hosseini Sarkhosh, S. M. (2014). Examining the effects of motivational and organizational determinants on knowledge-sharing behavior (Case study in an industrial research and development center). Iranian J. Inf. Proc. and Management, 30(40), 1084-1051.

Anandajayasekeram, P., \& Martella, D. R. (1999). Evaluation of agricultural research in Eastern, Central, and Southern Africa. Knowledge, Technology and Policy, 11(4), 13-41.

Erfanmanesh, M A., \& Keshavarzain, S. (2017). Publication delay of scholarly journals: a case for journals accredited by the Ministry of Science, Research \& Technology of Iran. Iranian Journal of Information Processing and Management, 33(1), 1-24

Fattahi, R. A. (2014). Conflict of scientometric indicators with economic/social development indicators. In: National Conference on Science Assessment: Predictability and Pathology (external scientific data), University of Isfahan, May 31 and June 1.

Garfield, E. (1970). Citation indexing for studying science. Nature, 227, 669-671.

Gaunand, A., Hocdé, A., Lemarié, S., Matt, M., \& Turckheim, E. (2015). How does public agricultural research impact society? A characterization of various patterns. Research Policy, 44(4), 849-861.

Gautam P. (2017). An overview of the Web of Science record of scientific publications (2004-2013) from Nepal: focus on disciplinary diversity and international collaboration. Scientometrics 113(3), 12451267.

Gazni, A., Hamidi Fard, N., \& Mehrad, J. (1391). Iranian scientific production and its comparison among the countries of the world the prediction of the growth of science production in Iran in 2018. Citation database of the science of the Islamic world. Shiraz.

Giorgis, S. (2015). Google Earth mapping exercises for structural geology students. A promising intervention for improving penetrative visualization ability. Journal of Geoscience Education, 63(2), 140-146.

Gizzi, F. T. (2015). Worldwide trends in research on the San Andreas Fault System. Arabian Journal of Geosciences. 8(12), 10893-10909.

Griffiths, J. K. (1993). Special Library: Increasing the Information Edge. In Special Libraries Association Work- 
shop. pp. 10-12.

Howard, A. S., Hatton, B., Reitsma, F., \& Lawrie, K. I. (2009). Developing a geoscience knowledge framework for a national geological survey organisation. Computers \& Geosciences, 35(4), 820-835.

Kashanian, R. (2013). Extracting and illustrating scientific cooperation in Geological Survey of Iran by studying the co-authorship networks of faculty members of this organization. Thesis. Islamic Azad University Science and Research Branch of Hamedan. 90p.

Kouziokas, G. N. (2015). Development of an information system as a GIS-Based Learning Environment for Geoscience and Geography Education. J. Technol. Learning, 22(4), 67-82.

Lanucara, S., Oggioni, A., Modica, G., Carrara, P. (2017). Interoperable sharing and visualization of geological data and instruments: a proof of concept. In: Intern. Conf. Computational Science and Its Applications. Proc... Springer Cham. pp. 584-599.

Li G. Q., \& Xiao K. Y. (2013). Virtual Demonstrating System of Geoscience Survey Teaching. In Applied Mechanics and Materials. Vol. 411 pp. 2309-2312. Trans Tech Publications.

Li L., Liu Y., Zhu H., Ying S., Luo Q., Luo H., \& Shen, H. (2017). A bibliometric and visual analysis of global geo-ontology research. Computers \& Geosciences, 99 1-8.

Loudon, T. V. (2006). The case for transforming the geological survey knowledge system: where digital spatial models meet the semantic grid. In: Sinha A. K. ed., 2006. Geoinformatics: Data to Knowledge: Geol. Soc. Am. Spec. Paper 397, 201-209.

Mirjalili, S.H., \& Osareh, F. (2012). Study of Scientometrics and Drawing the Historiography Map of the Articles of the Top Twenty Journals in the Field of Genetics and Inheritance during 2008-2000. Health Information Management, 1.75.

Nasseri, Z., \& Diani, M. H. (2010). Correlation between Scientifics research content update and consequence of delay in the publication of Iranian scientific/research journals. Librarianship and Information, 4.9.

Osareh, F., \& Wilson, C. S. (2002). Collaboration in Iranian scientific publications. Libri, 52(2), 88-98.

Osareh, F. (1998). Comparison of International Scientific Publications in developing Countries. Journal of Education and Psychology Shahid Chamran University Ahwaz, 5(1\&2), 19-30.

Penfield, T M., Baker, J., Scoble, R., \& Wykes, M. C. (2014). Assessment evaluations and definitions of research impact: A review. Research Evaluation 23(1), 21-32.

Qu, C.Y., Ye, H., \& Liu, Z. (2001). Basic principle of WebGIS and its application to geosciences. Seismology and Geology (in Chinese), 23(3), 447-454.

Reychav, I., \& Weisberg, J. (2010). Bridging intention and behavior of knowledge sharing. J. Knowledge Management, 14(2), 285-300.
Reynolds, S J., Piburn, M D., Leedy, D E., McAuliffe, C M., Birk J P., Johnson J. K. (2006). The Hidden Earth-Interactive computer-based modules for geoscience learning. Geol. Soc. Am. Spec, Papers 413:157170.

Reza gholi Lalani, Z. (2011). Considering of the status of scientific production of faculty members of Alzahra University diring 2005 to 2009 and influencing factors on scientific production. Master's thesis. Department of Library and Information. Faculty of Psychology and Educational Sciences. Al-Zahra University.

Ritschel, B., Mende, V., Gericke, L., Kornmesser, R., \& Pfeiffer, S. (2012). Web Approach for OntologyBased Classification Integration and Interdisciplinary Usage of Geoscience Metadata. Data Science Journal, 11, 140-153.

SCImago. (2012). Forecasting exercise: How World Scientific Output will be in 2018. http://www.scimagolab.com/blog/2012/forecasting-exercise-how-worldscientific -output-will-be-in2018/ (accessed Sep. 02 2015).

Seba, I., Rowley, J., \& Lambert, S. (2012). Factors affecting attitudes and intentions towards knowledge sharing in the Dubai Police Force. International Journal of Information Management, 32(4), 372-380.

Simons, B A., Raymond O., Jackson I., \& Lee K. (2012). One Geology-Improving global access to geoscience. Digital Soil Assessment and Beyond. Taylor \& Francis. p. 265-275.

Sinha, A K., Malik, Z., Rezgui, A., Barnes, C.G., Lin, K., Heiken, G., Thomas, W.A., Gundersen L.C., Raskin R., Jackson I., Fox P., McGuinness D., Seber D., \& Zimmerman H. (2010). Geoinformatics: transforming data to knowledge for geosciences. GSA Today, 20(12), 4-10.

Smith, D. R., \& Sutherland, A. (2002). Institutionalizing Impact Orientation: Building a Performance Management Approach that Enhances the Impact Orientation of Research Organizations. Chatham UK: Natural Resources Institute. Available online at: http:// r4d.dfid.gov.uk/pdf/outputs/R8086a.pdf (accessed Sep. 02 2015).

Sohail, M. S., Daud, S. (2009). Knowledge sharing in higher education institutions: Perspectives from Malaysia. Vine, 39(2), 125-142.

Song, R., \& Jiang, N. (2013). A web-based 3D geological information visualization system. In International Conference on Graphic and Image Processing (ICGIP 2012), Vol. 8768 p. 876811). International Society for Optics and Photonics.

Taber, M R., Ledley, T S., Lynds, S., Domenico, B., \& Dahlman L. (2012). Geoscience data for educational use: Recommendations from scientific/technical and educational communities. Journal of Geoscience Education, 60(3), 249-256.

Wilson, C. S., \& Osareh, F. (2003). Science and research in Iran: A scientometric study. Interdisciplinary Science Reviews, 28(1), 26-37. 